\title{
POLLEN TUBE GROWTH OF PAEONIA TENUIFOLIA L. (PAEONIACEAE) IN VITRO AND IN VIVO
}

\author{
FeruZan Dane AND Nuran Ekici ${ }^{*}$ \\ Department of Biology, Faculty of Science \& Arts, Trakya University, 22030, Edirne, Turkey
}

Key words: Paeonia tenuifolia, Pollen tube, In vitro growth, In vivo growth

\begin{abstract}
In vitro and in vivo studies on pollen germination of Paeonia tenuifolia L. (Paeoniaceae) revealed that pollen grains are shed at two-celled stage. Normal and abnormal pollens were observed. Pollen viability was recorded between 55 and $75 \%$. In vitro studies revealed $85 \%$ germination and usually the germination was monosphonic. Some pollen tubes with swollen tube tip and undulations were found. Styles and stigma were found to contain many pollen tubes $24 \mathrm{hrs}$ after pollination.
\end{abstract}

Cytological properties of anther wall, divisions of tapetum cells, micro-, macrosporogenesis (Dane 1997), early embryogeny (Dane and Olgun 1997), endosperm (Dane and Olgun 1998) in $P$. tenuifolia (Ranunculaceae) were previously studied. In this organisms some abnormalities were observed during micro- and macrosporogenesis (Dane 1997). The aim of this study is to examine the pollen morphology, viability, capacity of in vitro and in vivo pollen germination and cytological properties of pollen tubes in P. tenuifolia.

Paeonia tenuifolia L. (Paeoniaceae) was collected from the natural population near Edirne of European part of Turkey in May 2004. Pollen grains were collected after 24 hrs of pollination, which usually takes place early in the morning. Stigmas became receptive almost one day after the flower opened, and lasted for $24 \mathrm{hrs}$.

Pollen grains were stained following Mulugeta et al. (1994). Fertile (stained) and sterile (nonstained) pollens were counted from randomly chosen 30 regions. A total of 1923 pollen grains were counted. The cytological properties of generative and vegetative nuclei of pollen grains were investigated.

Hanging drop technique was used for culturing the pollen grains in liquid medium containing $10 \%$ sucrose and $0.01 \%$ boric acid (Vasil 1960). Cultures were incubated in room temperature $\left(25^{\circ} \mathrm{C}\right)$ and in diffuse laboratory light. The percentage of germinated pollen grains was counted after 12 hrs incubation in triplicate randomly from 100 - 200 grains (in groups of 25 or more from different fields on the slide).

Flowers were collected after 24 hrs of opening to determine the quantity of pollen grains on the pistil and in vivo pollen tube growth. After fixation in Carnoy $(3: 1)$, the pistils were kept in $70 \%$ ethanol. The pistils were hydrolized with $1 \mathrm{~N} \mathrm{HCI}$ for $15 \mathrm{~min}$ at $60^{\circ} \mathrm{C}$ in an oven. They were stained with Feulgen reagent for two hours in darkness at $25^{\circ} \mathrm{C}$. Then they were squashed and stained with aceto-orcein. Also they were examined with lactophenol-anilin blue, IKI and resorcin blue.

Pollen grains were prolate, tricolporatae, exine reticulatae and shed during the two-celled stage. The generative cell and vegetative nuclei were cresent and spherical, respectively (Fig. 1). Pollen viability was between 55 and $75 \%$ and showed variation in size as well as the degree of tube length. Pollens were 25.5 - $27.2 \mu \mathrm{m}$ long and 22.1 - $25.5 \mu \mathrm{m}$ broad. Sterile pollen grains were smaller in dimension.

*Corresponding author. Department of Science Education, Faculty of Education, Trakya University, 22030, Edirne, Turkey.<nuranekici@yahoo.com>. 

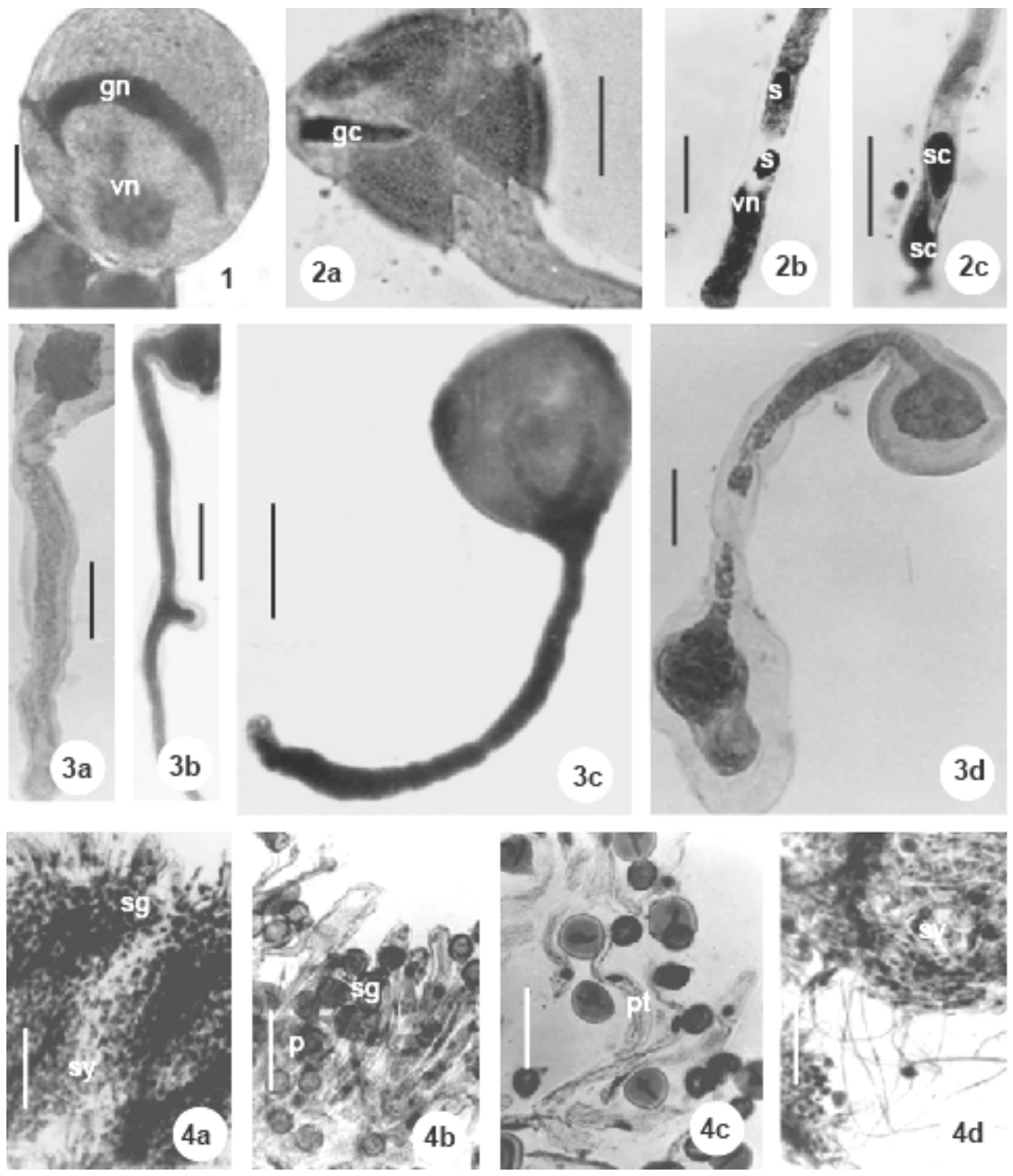

Figs 1-4. Pollen grain and in vitro and in vivo germination of Paeonia tenuifolia L. 1. Pollen grain. 2a. Newly generated pollen tube. 2b. Vegetative nucleus and sperm nuclei in the pollen tube. 2c. Sperm cells. 3a-d. Abnormal pollen. 4a-d. In vivo pollen germination. (gc, generative cell; s, sperm; sc, sperm cells; vn, vegetative nucleus, p, pollen; pt, pollen tube; sg, stigma; sy, style). Bars in Figs 1, 4a, d = 10 $\mu \mathrm{m}$; 2a-c, 3a-d, $4 \mathrm{~b}=20 \mu \mathrm{m}, 4 \mathrm{c}=15 \mu \mathrm{m}$.

In vitro pollen germination was slow and started between 20 and 30 min after transfer in the medium. It was revealed that $85 \%$ of pollen grains were germinated usually with only one pollen tube (Fig. 2a). Some abnormal pollen tubes were observed with swollen tube tips and weak and undulating tubes (Fig. 3a-d). These abnormalities were found in $10-20 \%$ pollens. 
Vegetative and generative nuclei were observed easily within the growing pollen tube where generative nucleus divides into two sperm nuclei (Fig. 2b). Sperm cells were also seen (Fig. 2c).

The pollen tube germination was generally normal (Fig. 4a-d). Many pollen tubes were recorded on the stigma and styles but a few in the ovary chamber. In vivo studies showed that there was no self-incompatibility. These observations are similar to that reported in $P$. jishanensis (Zhou et al. 1999).

\section{References}

Dane F 1997. Cytological and cytoembryological studies on Paeonia tenuifolia L. Tr. J. Bot. 21: 291-303.

Dane F and G Olgun 1997. The embryogeny of Paeonia tenuifolia (Paeoniaceae). Bocconea. 5: 557-562.

Dane F and G Olgun 1998. Light and electron microscope studies of structure and functions of ovules of Paeonia tenuifolia L. (Paeoniaceae). Marmara Univ. J. Sci. 14: 11-38.

Mulugeta D, BD Maxwell, PK Fay and WE Dyer 1994. Kochia (Kochia scoparia) pollen dispersion, viability and germination. Weed Sci. 42: 548-552.

Vasil IK 1960. Studies on pollen germination of certain cucurbitaceae. Am. J. Bot. 47: 239-248.

Zhou SL, DY Hong and KY Pan 1999. Pollination biology of Paeonia jishanensis T. Hong \& W.Z. Zhao (Paeoniaceae), with special emphasis on pollen and stigma biology. Bot. J. Lin. Soc. 130(1): 43-52. 